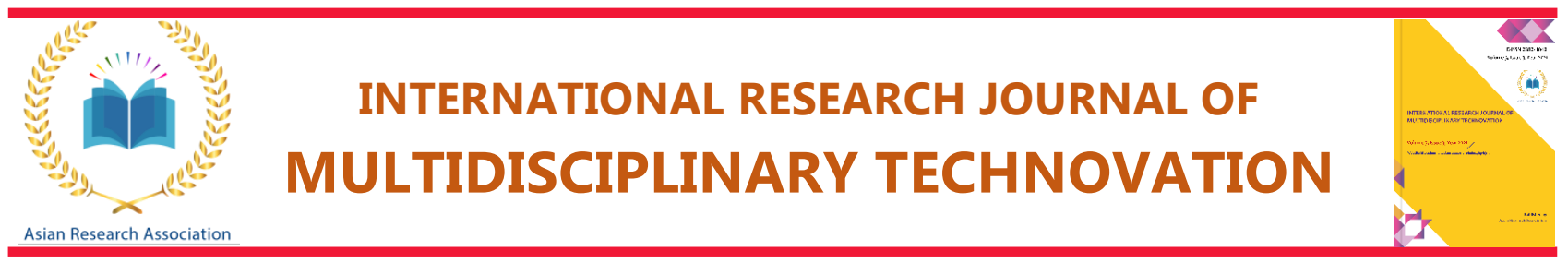

\title{
Comparative Assessment of Deformation Under Plate Bearing Test and CBR Test for Subgrade Soil
}

\author{
Saad Issa Sarsam 1, 2, * \\ ${ }^{1}$ Sarsam and Associates Consult Bureau (SACB), Baghdad, Iraq. \\ ${ }^{2}$ Formerly at Department of Civil Engineering, College of Engineering, University of Baghdad, Iraq. \\ ${ }^{*}$ Corresponding authors email: saadisasarsam@coeng.uobaghdad.edu.iq \\ DOI: https://doi.org/10.54392/irjmt2161 \\ Received: 20-05-2021, Revised: 12-07-2021; Accepted: 12-08-2021, Published: 16-10-2021
}

Abstract: A significant variation in the strength and deformation behavior of subgrade soil when tested in the laboratory and in the field. However, correlation of such variables is essential to evaluate the quality of the constructed subgrade. An attempt has been made in the present investigation to assess the deformation of control and stabilized subgrade soil in the laboratory and in the field. California bearing ratio (CBR) test was conducted in the laboratory and the static plate bearing test (PBT) was conducted in the field. Subgrade soil samples were stabilized with $6 \%$ lime, $17 \%$ Cationic Emulsion, and combination of lime and emulsion. Similar stabilization was conducted at test sections in the field. The behavior of the control and stabilized soil in deformation under static PBT in the field and CBR in the laboratory was monitored and evaluated. It was noticed that polynomial correlation exists with high coefficient of determination between laboratory and field deformation for stabilized soil. It was observed that the deformation under CBR test decreased after implication of lime by (96 and 88) \% for unsoaked and soaked testing conditions respectively. The deformation decreases by (92 and 85.6) \% for unsoaked and soaked testing conditions respectively when emulsion was implemented. The deformation decreases by ( 91 and 88) \% for unsoaked and soaked testing conditions respectively when combined stabilization was implemented. However, the deformation under PBT decreases by $(75,56$, and 50$) \%$ for lime, emulsion, and combined stabilization processes respectively. It was concluded that testing condition (soaked or unsoaked) has no significant impact on the deformation of stabilized soil while it has a significant influence on the deformation of untreated soil under CBR test. On the other hand, the deformation of control soil shows no significant variation among field and laboratory testing in the model, however, the stabilized soil samples exhibit higher influence of field deformation on the polynomial models.

Keywords: Stabilization, Lime, Emulsion, Plate load, CBR, Subgrade, Deformation.

\section{Introduction}

The comparison of laboratory and in-situ equipment for the determination of soil subgrade strength and deformation is a practical and effective method to ensure that the soil subgrade is properly compacted and achieved the required design strength. Al-Khashab and, Al-Hayale, [1] treated soil with (0.5, 1.0 , and $1.5 \%$ ) lime addition by weight. After short period, emulsified asphalt was added with different percentages namely (2, 4, 6 and 8) by weight of soil. The test result of lime addition alone showed that there was a considerable reduction in soil plasticity, $1.5 \%$ of lime addition converted the soil towards non-plastic types. However, the emulsified asphalt addition to the mixture, caused slight increase in the plasticity but, their values in the whole, remained below the value of the natural soil. Arshad et al., [2] correlates laboratory and in-situ CBR values of subgrade soil. The field results obtained were then compared and analyzed with the laboratory CBR for both unsoaked and soaked values. It was found that there is a reasonable relationship between the in-situ CBR and the laboratory unsoaked CBR values. Seyman, [3] evaluated the Light Falling Weight Deflectometer and the Dynamic Cone Penetrometer as potential tests to measure in-situ stiffness of highway materials and embankments. It was concluded that significant experience was gained with these devices after conducting laboratory tests together with the plate load and CBR tests as a basis for comparison. Several correlations were developed and the conclusions for each investigated device will be presented separately. 
Hajiannia et al., [4] presented logical correlation between the Plate Load Test PLT and California Bearing Ratio (CBR) test using the numerical modeling of the CBR test in the ABAQUS software finite element environment and performing some PLTs in the site. Results have shown that the PLT load- deflection curve has been predicted with a high degree of accuracy. It was concluded that based on the number of the PLTs performed in the site, an economic analysis was done which showed that the test results can be implemented with great savings in the costs. Kuttah, [5] demonstrated that the laboratory dynamic California bearing ratio CBRLD test can be used as a method of compaction assessment of selected subgrade soil. Moreover, it has been demonstrated in this study that the CBRLD can strongly be correlated to the compaction densities and molding water contents using polynomial correlation and a best-fit multiple regression model for a wide range of molding water contents. In addition, the repeatability of the dynamic laboratory CBR test was examined as discussed.

A series of field tests, including California Bearing Ratio (CBR) test, plate loading test, Benkelman beam deflection test, and dynamic cone penetrometer (DCP) test were undertaken by Du et al., [6] after the embankment construction. The results indicated that in the top zone of the filled soil layers with $94 \%$ degree of compaction, the quick lime stabilized subgrade soil exhibited higher values of CBR and resilient modulus, and lower values of resilient deflection and DCP Index. Sarsam et al., [7] revealed that collapsible soil was mixed with asphalt emulsion, lime, and combinations of lime and asphalt emulsion and tested in the laboratory for California bearing ratio in dry and soaked conditions. Field trial sections have been prepared with the same combinations and subjected to plate bearing test. The influence of combined stabilization on the structural properties in terms of load bearing capacity under both testing techniques have been monitored and analyzed. It was concluded there is no significant variation in the strength behavior and resistance to deformation between combined stabilization and asphalt stabilization at soaked condition.

The aim of the present investigation is to assess the deformation of control and stabilized subgrade soil in the laboratory and in the field. Plate bearing test and CBR test will be implemented.

\section{Materials and Methods}

\section{Subgrade Soil}

Subgrade soil was obtained from AL-Nasiriya city, south of Baghdad. The top $30 \mathrm{~cm}$ soil was removed before obtaining the soil sample and the soil was obtained from a depth of (1.0 upto1.5) $\mathrm{m}$ below the natural ground level. The physical properties of the subgrade soil are evaluated according to ASTM, [8] standards and listed in Table 1. The chemical composition of the soil is illustrated in Table 2.

Table 1. Physical properties of the soil

\begin{tabular}{|l|l|}
\hline Physical Properties & Test Results \\
\hline Liquid limit \% & 47 \\
\hline Plastic limit \% & 23 \\
\hline Plasticity index \% & 24 \\
\hline Specific gravity & 2.730 \\
\hline Clay content \% & 42 \\
\hline Silt content \% & 57 \\
\hline Sand content \% & 1 \\
\hline Unified soil classification & $\mathrm{CL}$ \\
\hline AASHTO soil classification & $\mathrm{A}-7-6$ \\
\hline Maximum dry density kN/m ${ }^{3}$ & 16.6 \\
\hline Optimum moisture content \% & 20 \\
\hline Collapse potential \% & 5.5 \\
\hline $\begin{array}{l}\text { Unconfined compressive strength } \\
\text { (Dry test) kPa }\end{array}$ & 121 \\
\hline $\begin{array}{l}\text { Unconfined compressive strength } \\
\text { (Absorbed test) kPa }\end{array}$ & 20 \\
\hline
\end{tabular}

Table 2 Chemical composition of the soil

\begin{tabular}{|l|l|}
\hline Chemical Composition & Test Result \\
\hline $\mathrm{SiO}_{2} \%$ & 40.2 \\
\hline $\mathrm{Fe}_{2} \mathrm{O}_{3} \%$ & 6 \\
\hline $\mathrm{Al}_{2} \mathrm{O}_{3} \%$ & 11.2 \\
\hline $\mathrm{CaO} \%$ & 17.3 \\
\hline $\mathrm{MgO} \%$ & 5.9 \\
\hline Organic content \% & 0.56 \\
\hline Loss on ignition \% & 15.9 \\
\hline Total soluble saults \% & 1.2 \\
\hline $\mathrm{PH}$ Value & 8.2 \\
\hline
\end{tabular}

\section{Hydrated Lime}

Hydrated lime was obtained from local market and implemented in the present investigation. The physical properties and chemical compositions are presented in Table 3. 


\section{Emulsified asphalt}

This type of liquid asphalt is cationic emulsion, it was obtained from Al-Dourah refinery. This type of liquid asphalt was selected since it provides easy mixing with soil, and ultimately a homogenous mixing is obtained. Properties of emulsified asphalt used as supplied by refinery are listed in Table 4 .

Table 3. Chemical Composition and Physical Properties of Hydrated Lime

\begin{tabular}{|l|l|}
\hline Chemical composition & Test results \\
\hline $\mathrm{SiO}_{2}$ & 1.51 \\
\hline $\mathrm{Fe}_{2} \mathrm{O}_{3}$ & 0.11 \\
\hline $\mathrm{Al}_{2} \mathrm{O}_{3}$ & 0.93 \\
\hline $\mathrm{CaO}$ & 92.01 \\
\hline Loss on ignition \% & 8.9 \\
\hline \% passing sieve No. 200 & 89 \\
\hline Specific gravity & 2.60 \\
\hline
\end{tabular}

Table 4. Properties of asphalt emulsion

\begin{tabular}{|l|l|}
\hline Property & Test results \\
\hline Particle charge & Positive \\
\hline Viscosity (Cst.) & 45 \\
\hline Setting time (Hours) & 19 \\
\hline Coating ability and water resistance & Good \\
\hline Coating dry and wet aggregates & Fair \\
\hline
\end{tabular}

\section{Testing Methods}

The CBR test was conducted according to ASTM, [9] to study the effect of stabilization on the deformation of soil. Eight samples were prepared in four groups. In the first group, two samples are prepared of control soil (untreated) with optimum moisture content $20 \%$. For the second group, two samples were prepared with optimum percentage of fluid content $(17 \%$ cationic emulsified asphalt $+3 \%$ water). For the third group, two samples were prepared with optimum hydrated lime content of $6 \%$. For the fourth group, two sample were prepared with combined stabilization, (6\% lime $+17 \%$ emulsion $+3 \%$ water). Details of obtaining the optimum stabilizer content could be found at Sarsam et al., [7]. The prepared samples were tested under soaked and unsoaked test conditions.

\section{Unsoaked Test}

The specimens were left after compaction for curing at room temperature of $25 \pm 1^{\circ} \mathrm{C}$ for 7 days in the mold. Only the top surface of the specimens was subjected to curing as recommended by Sarsam, [10]. This situation may represent the field conditions since only the top compacted surface will cure at room temperature before testing. Such curing period was required for the chemical reaction of lime with the soil for lime stabilized samples, and for evaporation of volatiles from the asphalt stabilized samples.

\section{Soaked Test}

The specimens could cure at room temperature for 7 days and then soaked in water for 4 days at room temperature. Then the soaked specimens were removed from water, allowed to drain for 15 minutes, and tested at room temperature. Load deformation curves were drawn and analyzed.

\section{Static Plate Bearing Test in the Field}

Static field Plate bearing test is commonly used to predict the deformations and failure characteristics of the subgrade soil and modulus of subgrade reaction. It was conducted in the field according to AASHTO, [11] procedure. The same site from which soil samples were obtained, was implemented for the field test sections. The top $30 \mathrm{~cm}$ of the soil was removed, the soil was pulverized, divided into four test sections, and the required moisture was added and mixed, then the required stabilization agent was implicated, mixed and compacted. Details of site preparation could be referred at Sarsam et al., [7]. Figure 1 exhibit the static field PBT, and the laboratory CBR apparatus.

\section{Results and Discussions}

Table 5 exhibit the test variables, it can be noted that loading area of the soil in the field using plate bearing test is 23.5 folds higher than that of the soil tested in CBR mold at the laboratory, the maximum deformation that was attained in the field is 2.7 folds higher than that obtained in the laboratory testing. On the other hand, the maximum load applied in the field is 5.5 folds higher than that implemented in the laboratory.

\section{Deformation Under CBR Test}

As demonstrated in Figure 2, the control soil sample (untreated) exhibit low potential of load sustaining ability accompanied with high deformation for both soaked and unsoaked testing conditions. However, when the soil was treated with $6 \%$ of 
hydrated lime, it exhibits improvement in the load sustaining capacity with lower deformation. This could be attributed to the fact that when soil was mixed with lime, a pozzolanic or cementing action took place and lime react chemically with available silica and alumina in soil which can form natural cement composed of calcium alumina-silicate complex compound.
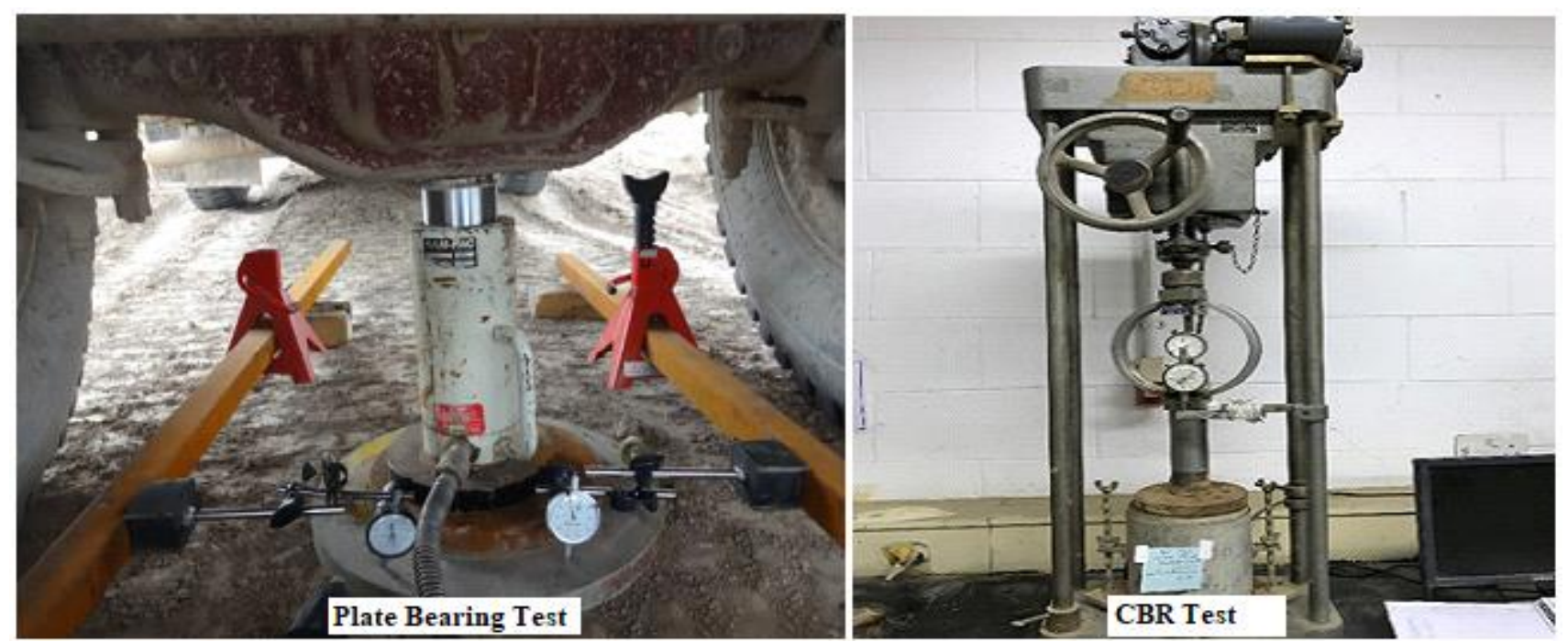

Figure 1. Static plate bearing test in the field and CBR Test.

Table 5. Test Variables

\begin{tabular}{|l|l|l|}
\hline Test Variables & California Bearing Ratio Test & Static Plate Bearing Test \\
\hline Loading area $\left(\mathrm{cm}^{2}\right)$ & 19.35 & 456.2 \\
\hline Maximum deformation $(\mathrm{mm})$ & 13 & 35 \\
\hline Applied load $(\mathrm{kN})$ & 90 & 500 \\
\hline Testing conditions & Unsoaked and Soaked & Unsoaked \\
\hline Testing Technique & Laboratory & Field \\
\hline
\end{tabular}
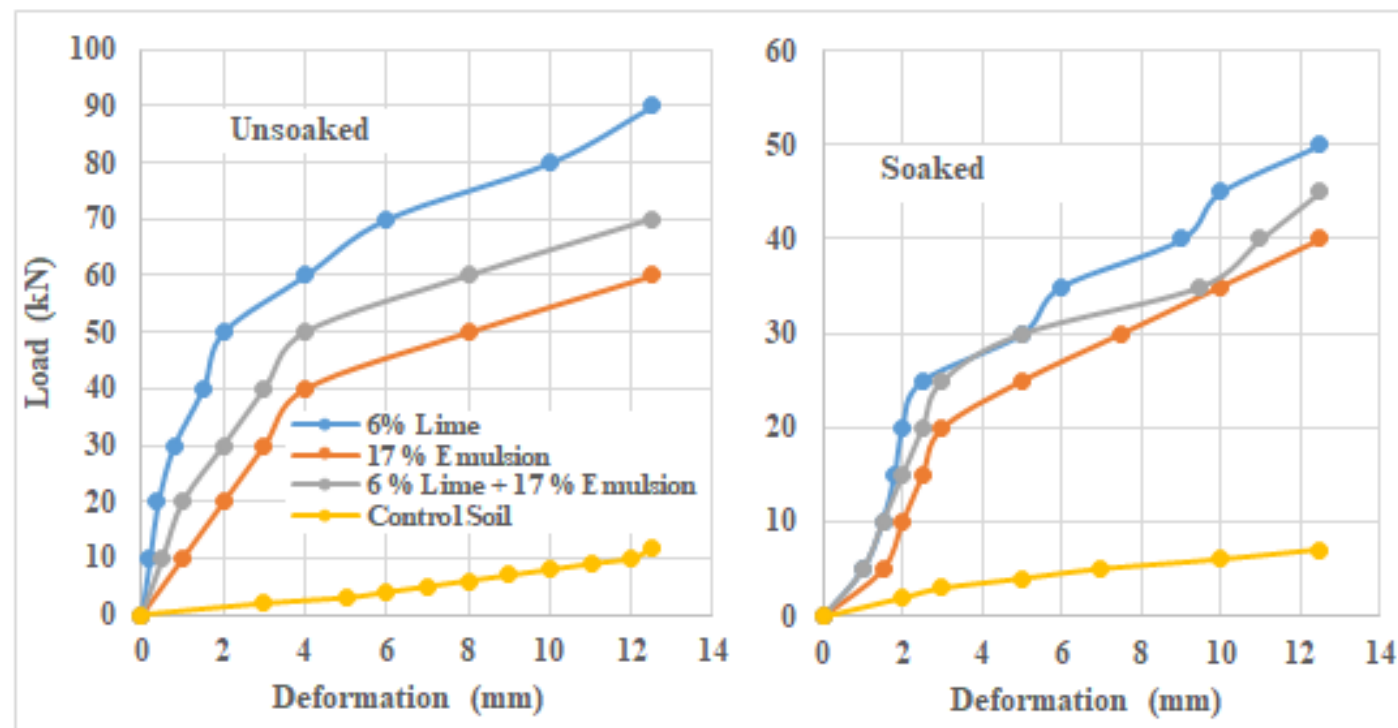

Figure 2. Deformation under California Bearing Ratio Test 
Table 6. Deformation Models Between Soaked and Unsoaked CBR Test C

\begin{tabular}{|l|l|l|}
\hline Type of soil mixture & Mathematical Model & Coefficient of Determination \\
\hline Control Soil (Untreated) & $\mathrm{Y}=0.0217 \mathrm{X}^{2}-0.7522 \mathrm{X}+1.7351$ & 0.993 \\
\hline Soil $+6 \%$ Lime & $\mathrm{Y}=-0.0259 \mathrm{X}^{2}+1.0779 \mathrm{X}+0.6605$ & 0.988 \\
\hline Soil $+17 \%$ Emulsion & $\mathrm{Y}=-0.0016 \mathrm{X}^{2}+0.555 \mathrm{X}+0.7737$ & 0.994 \\
\hline Soil $+6 \%$ Lime $+17 \%$ Emulsion & $\mathrm{Y}=0.2177 \mathrm{X}^{2}-0.7522 \mathrm{X}+1.7351$ & 0.993 \\
\hline
\end{tabular}

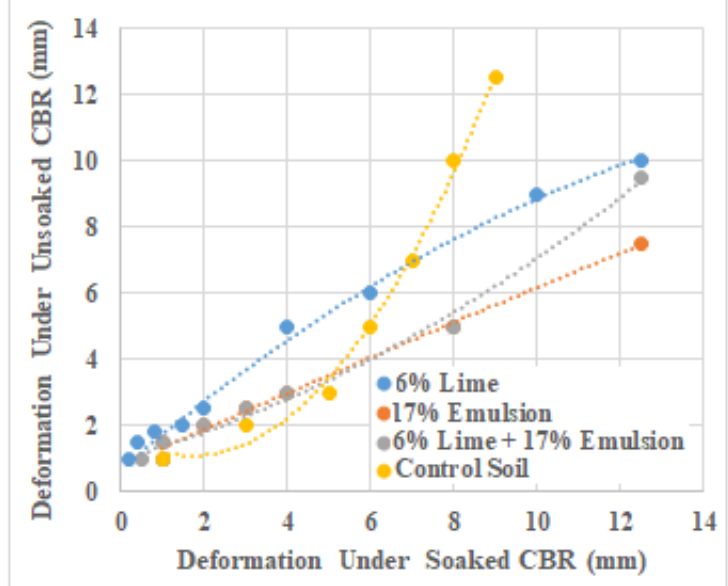

Figure 3. Deformation under Unsoaked and Soaked CBR

This increment was due to the formation of cementations compounds between the silicates and aluminates from lime and soil. Such finding agrees with the work reported by Al-Khashab and Al-Hayalee, [1]. It can be observed that at $10 \mathrm{kN}$ load, the deformation decreased by $96 \%$ when $6 \%$ lime was implemented for unsoaked testing condition. Similar behavior could be detected for specimen tested at soaked condition and the deformation decreases by $88 \%$ after implication of lime at $8 \mathrm{kN}$ load. On the other hand, when cationic emulsion was implemented as a stabilizing agent, the deformation decreases by $92 \%$ when $17 \%$ emulsion was implemented for unsoaked testing condition at $10 \mathrm{kN}$ load. Similar behavior could be detected for specimen tested at soaked condition and the deformation decreases by $85.6 \%$ after implication of emulsion at $8 \mathrm{kN}$ load. This could be attributed to the adhesion of binder with soil particles. Similar behavior was reported by Kuttah [5].

Finally, when combined stabilization $(6 \%$ lime $+17 \%$ emulsion) was implemented as stabilizing agent, the deformation decreases by $91 \%$ for unsoaked testing condition as compared to control soil at $10 \mathrm{kN}$ load. The soaked testing condition exhibit similar behavior and the deformation decreases by $88 \%$ at 8 $\mathrm{kN}$ load. This may be attributed to the waterproofing properties of soil when emulsion asphalt was added and cementations compounds between the silicates and aluminates from lime and soil. Generally, stabilization of the soil exhibit gentle increment in deformation up to $4 \mathrm{~mm}$, then the rate of deformation increases sharply regardless of the stabilizing agent or the testing condition. Figure 3 exhibit the models corelating the deformation of soil under soaked and unsoaked testing conditions. The polynomial second degree equations shown in Table 6 exhibit high coefficient of determination for control and stabilized soil.

It can be observed that stabilization process was able to control the variation in deformation under CBR test between soaked and unsoaked testing conditions within $(40-45)^{\circ}$ while the relationship of control soil sample was set far from the $45^{\circ}$ line. It can be concluded that testing condition (soaked or unsoaked) has no significant impact on the deformation of stabilized soil while it has a significant influence on the deformation of untreated soil. This can be attributed to the fact that cementation process of soil particles with lime or asphalt has changed the overall structure and properties of the soil.

\section{Deformation Under Plate Bearing Test}

Figure 4 exhibit the deformation of control and stabilized soil under plate bearing test, it can be detected that implication of $17 \%$ emulsion was able to reduce the deformation by $56 \%$ under $420 \mathrm{kN}$ load as compared to the control soil. This may be attributed to the created shear strength due to adhesion of asphalt 
binder with soil particles. However, $6 \%$ lime was able to enhance the quality of the subgrade and exhibits the lowest deformation. The deformation of lime stabilized soil was lower than that of asphalt stabilized soil by 75 $\%$. This could be attributed to the chemical reaction of lime with soil ingredients like silica and alumina and the presence of moisture to enhance the reaction process. When the combined stabilization (6\% lime $+17 \%$ Emulsion) was implemented, the deformation decreases by $50 \%$ as compared to asphalt stabilization.

In general, the deformation of the control soil increases sharply as the loading proceeds while the deformation rate is gently increase after stabilization. Meanwhile, the failure of the stabilized soil occurs at lower deformation and higher load as compared with the control soil. This indicates stiffer mixture obtained after stabilization regardless of the stabilizing agent implemented. When comparing the deformation of the soil between field and laboratory test, it can be revealed that similar trend of deformation could be noticed but with variable loading potential. The deformation under CBR test is restricted by the mold dimensions and the surcharge load around the penetration piston. However, there is no surcharge load around the plate of the field plate bearing test, the deformation is also not restricted in the horizontal direction. This could be the reason of achieving higher deformation in case of field testing as compared with that of laboratory testing.

\section{Corelaion Between Field and Laboratory Measured Deformation}

Figure 5 exhibit the variation between field and laboratory deformation and the mathematical models are listed in Table 7 . It can be observed that the polynomial second degree equations exhibit high coefficients of determination regardless of the stabilizer type. It can be noted that the control soil shows a model that almost matching the $45^{\circ}$ line. Similar findings were reported by Arshad et al., [2]. However, the stabilized soil samples exhibit higher influence of field deformation on the models. The highest impact on the deformation could be detected from lime stabilization, this could beattributed to the stiffness inherted due to chemical reaction between lime and the silica and alomina ingradents of the soil. The combined stabilization exhibit lower influence on the deformation model since the emulsion will balance the impact of lime on the properties of the stabilized soil. The emulsion stabilized soil exhibit the lowest impact since the asphalt will provide flexibility to the soil. such findings agrees well with Hajiannia et al., [4].

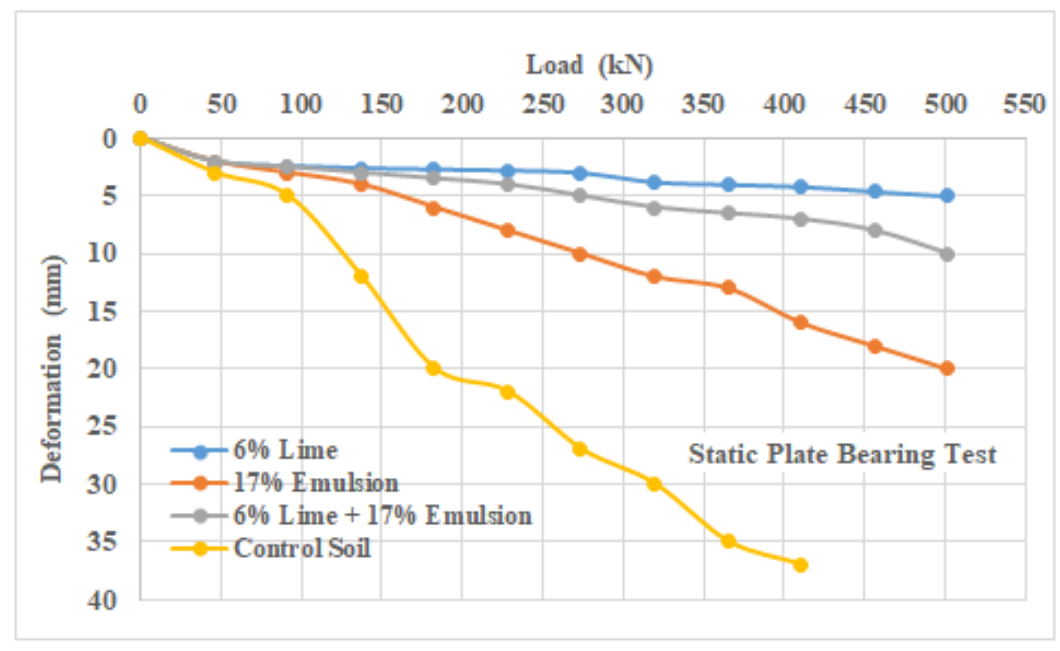

Figure 4. Deformation under Plate Bearing Test

Table 7. Deformation Models for Control and Stabilized Soil

\begin{tabular}{|l|l|l|}
\hline Type of soil mixture & Mathematical Model & Coefficient of Determination \\
\hline Control Soil (Untreated) & $\mathrm{Y}=-0.0595 \mathrm{X}+1.7981 \mathrm{X}-0.4088$ & 0.994 \\
\hline Soil $+6 \%$ Lime & $\mathrm{Y}=2.0186 \mathrm{X}^{2}-7.224 \mathrm{X}+6.3153$ & 0.960 \\
\hline Soil $+17 \%$ Emulsion & $\mathrm{Y}=0.1363 \mathrm{X}^{2}-0.2455 \mathrm{X}+1.2124$ & 0.991 \\
\hline Soil $+6 \%$ Lime $+17 \%$ Emulsion & $\mathrm{Y}=0.6206 \mathrm{X}^{2}-1.9939 \mathrm{X}+2.235$ & 0.998 \\
\hline
\end{tabular}




\section{Conclusions}

Based on the limitation of testing program and the properties of materials, the following conclusions can be addressed.

1. The deformation under $\mathrm{CBR}$ test decreased after implication of $6 \%$ lime by (96 and 88 ) \% for unsoaked and soaked testing conditions respectively.

2. The deformation decreases by (92 and 85.6 ) \% for unsoaked and soaked testing conditions respectively when $17 \%$ emulsion was implemented.

3. The deformation decreases by ( 91 and 88$) \%$ for unsoaked and soaked testing conditions respectively when combined stabilization (6\% lime $+17 \%$ emulsion) was implemented.

4. The deformation under PBT decreases by $(75$, 56 , and 50 ) \% for lime, emulsion, and combined stabilization processes respectively.

5. Testing condition (soaked or unsoaked) has no significant impact on the deformation of stabilized soil while it has a significant influence on the deformation of untreated soil under CBR test.

6. The deformation of control soil shows no significant variation among field and laboratory testing in the model, however, the stabilized soil samples exhibit higher influence of field deformation on the polynomial models.

\section{References}

[1] M. Al-Khashab, M. Al-Hayalee, Stabilization of Expansive Clayey Soil Modified by Lime with an Emulsified Asphalt Addition, Engineering \& Technology, 26(10) (2008).

[2] A. Arshad, E. Shaffie, F. Ismail, W. Hashim, N. Mat Daud, Z. Abd Rahman, Comparative evaluation of soil subgrade strength using laboratory and in-situ tests, International Journal of Civil Engineering and Technology, 9(7) (2018) 1184-1191.

[3] E. Seyman, (2003) Laboratory evaluation of insitu tests as potential quality control/quality assurance tools, MSc. Thesis, Louisiana State University and Agricultural and Mechanical College, Louisiana.

[4] A. Hajiannia, M.T. Dorobati, S. Kasaeian, S.B. Baghbadorani, Correlation between the results of the PLT and CBR tests to determine the elasticity modulus, In Proceedings of the $5^{\text {th }}$ International Conference on Geotechnical and Geophysical Site Characterisation, ISC 2016,
Australian Geomechanics Society, (1) (2017) 701-706.

[5] D. Kuttah, Strong correlation between the laboratory dynamic CBR and the compaction characteristics of sandy soil, International Journal of Geo-Engineering, 10(1) (2019) 1-13. [DOl]

[6] Y. Du, N. Jiang, S. Liuc, S. Horpibulsuk, A. Arulrajah, Field evaluation of soft highway subgrade soil stabilized with calcium carbide residue, Soils and Foundations, 56 (2016) 301 314. [DOI]

[7] S. Sarsam, A. Al-Saidi, A. Al Taie, Influence of Combined Stabilization on the Structural Properties of Subgrade Soil, Journal of Geotechnical Engineering, 4(1), (2017) 13 -24.

[8] ASTM D2487, (2017) Standard practice for classification of soils for engineering purposes (unified soil classification system), ASTM International, West Conshohocken.

[9] ASTM D1883-07, (2007) Standard Test Method for CBR (California Bearing Ratio) of Laboratory-Compacted Soils, American Society for Testing and Materials (ASTM), West Conshohocken, PA.

[10] S. Sarsam, The role of Cationic emulsion in the strength characteristics of Gypseous soils. Proceedings, 8TH International Conference on Material Sciences (CSM8-ISM5), UNESCO Palace, Beirut-Lebanon, May 28-30, (2012).

[11] AASHTO T222, (2007) Nonrepetitive static plate load test of soil and flexible pavement components for use in evaluation and design of airport and highway pavements, American Association of State Highway and Transportation Officials, Washington, DC

\section{Funding}

No funding was received for conducting this study.

\section{Conflict of interest}

The Author has no conflicts of interest to declare that they are relevant to the content of this article.

\section{Does this article screened for similarity?}

Yes

About the License

(C) The author 2021. The text of this article is open access and licensed under a Creative Commons Attribution 4.0 International License 